\title{
Correction to: Weight Regain After Gastric Plication: Reoperative Sleeve Gastrectomy or Roux-en-Y Gastric Bypass?-Analysis of 116 Consecutive Cases
}

Elias Chahine ${ }^{1}$ - Mubarak Alkandari ${ }^{2}$. Belinda De Simone ${ }^{1} \cdot$ Mazen Dirani ${ }^{1}$ - Antonio D'alessandro ${ }^{1}$. Elias Saikaly ${ }^{3}$. Andrew Gumbs ${ }^{1}$ • Maria Cristina Cartillone ${ }^{1} \cdot$ Luigi Prisco $^{1}$ - Marc Anthony Chouillard ${ }^{1} \cdot$ Radwan Kassir $^{4}$. Elie Chouillard ${ }^{1}$

Published online: 26 June 2020

(C) Springer Science+Business Media, LLC, part of Springer Nature 2020

\section{Correction to: Obesity Surgery}

https://doi.org/10.1007/s11695-020-04767-y

In the original article the name of author Luigi Prisco was incorrect. It is correct here.

Publisher's Note Springer Nature remains neutral with regard to jurisdictional claims in published maps and institutional affiliations.

The online version of the original article can be found at https://oi.org/ 10.1007/s11695-020-04767-y

Elias Chahine

dr_elias_chahine@hotmail.com

1 Department of Minimally Invasive Surgery, Poissy Saint Germain Medical Center, 10 rue du Champ Gaillard, 78300 Poissy, France

2 Department of General Surgery, AlSabah Hospital, Kuwait City, Kuwait

3 Saint George Hospital University Medical Center, University of Balamand, Beirut, Lebanon

4 Department of General Surgery, CHU Felix-Guyon, St-Denis, La Reunion, France 